EOMmUn: Communication et organisation

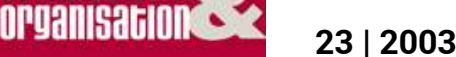

Modèles de communication Homme-Animal

\title{
Du coche au coach le cheval et le manager
}

Hélène Dufau

\section{OpenEdition}

Journals

Édition électronique

URL : http://journals.openedition.org/communicationorganisation/2856

DOI : 10.4000/communicationorganisation.2856

ISSN : 1775-3546

Éditeur

Presses universitaires de Bordeaux

Édition imprimée

Date de publication : 1 mai 2003

Pagination : 222-228

ISSN : 1168-5549

Référence électronique

Hélène Dufau, « Du coche au coach le cheval et le manager », Communication et organisation [En ligne], 23 | 2003, mis en ligne le 27 mars 2012, consulté le 04 mai 2019. URL : http:// journals.openedition.org/communicationorganisation/2856 ; DOI : 10.4000/ communicationorganisation. 2856

Ce document a été généré automatiquement le 4 mai 2019.

(C) Presses universitaires de Bordeaux 


\title{
Du coche au coach le cheval et le manager
}

\author{
Hélène Dufau
}

\section{RÉSUMÉS}

La connaissance des mécanismes de communication chez les chevaux peut mener à des applications inattendues : deux formateurs à l'équitation ont élaboré, avec l'aide de praticiens du coaching, un protocole grâce auquel ils peuvent faire prendre conscience à des cadres de leurs attitudes et comportements dans les situations de leadership. Cette démarche peut orienter, avec l'aide de spécialistes (coach ou thérapeutes), l'évaluation et le développement personnel.

Knowing how horses communicate can produce unexpected developments : two horse-riding trainers have elaborated, with the help of specialists in coaching, a program through which they allow managers to become aware of their attitudes and behaviors in situation where they have to exert their leadership. This process. when taken up by specialists (therapists or couches) may help assessment of personal qualities. and personal development.

\section{INDEX}

Mots-clés : attitude, coaching, communication homme/animal., comportement de communication, développement personnel, équitation, leadership 